\title{
Shear bond strengths of aged and non-aged CAD/CAM materials after different surface treatments
}

\author{
Hamiyet Kilinc ${ }^{1 *}$, Fatma Ayse Sanal ${ }^{1}$, Sedanur Turgut ${ }^{2}$ \\ ${ }^{1}$ Department of Prosthodontics, Faculty of Dentistry, Bolu Abant Izzet Baysal University, Bolu, Turkey \\ ${ }^{2}$ Department of Prosthodontics, Faculty of Dentistry, Karadeniz Technical University, Trabzon, Turkey
}

\begin{abstract}
PURPOSE. To assess shear bond strengths (SBS) of resin composites on aged and non-aged prosthetic materials with various surface treatments. MATERIALS AND METHODS. Cerasmart (CE), Vita Enamic (VE), Vita Mark II $(\mathrm{VM})$, and IPS e.max CAD (EC) blocks were sliced, and rectangular-shaped specimens $(14 \times 12 \times 1.5 \mathrm{~mm} ; \mathrm{N}=$ 352) were obtained. Half of the specimens were aged (5000 thermal cycles) for each material. Non-aged and aged specimens were divided into 4 groups according to the surface treatments (control, air abrasion, etching, and laser irradiation; $\mathrm{n}=11$ ) and processed for scanning electron microscopy (SEM). The repair procedure was performed after the surface treatments. SBS values and failure types were determined. Obtained data were statistically analyzed $(P \leq .05)$. RESULTS. The material type, surface treatment type, and their interactions were found significant with regard to SBS $(P<.001)$. Aging also had a significant effect on prosthetic material-resin composite bonding $(P<.001)$. SBS values of non-aged specimens ranged from 12.16 to $17.91 \mathrm{MPa}$, while SBS values of aged specimens ranged from 9.46 to $15.61 \mathrm{MPa}$. Non-aged VM in combination with acid etching presented the highest score while the control group of aged CE showed the lowest. CONCLUSION. Etching was more effective in achieving durable SBS for VM and EC. Laser irradiation could be considered as an alternative surface treatment method to air abrasion for all tested materials. Aging had significant effect on SBS values generated between tested materials and resin composite. [J Adv Prosthodont 2020;12:273-82]
\end{abstract}

KEYWORDS: Bond strength; Computer-aided design and computer-aided manufacturing (CAD/CAM); Laser; Repair; Surface treatment; Thermal aging

\section{INTRODUCTION}

With the abundance of innovations in digital dental technology, alternatives for chairside computer-aided design and computer-aided manufacturing $(\mathrm{CAD} / \mathrm{CAM})$ materials have rapidly increased in the dental market, including ceramics, resin ceramics, and resin composites. ${ }^{1,2}$ Especially the resin ceramics have gained interest in prosthodontics in recent

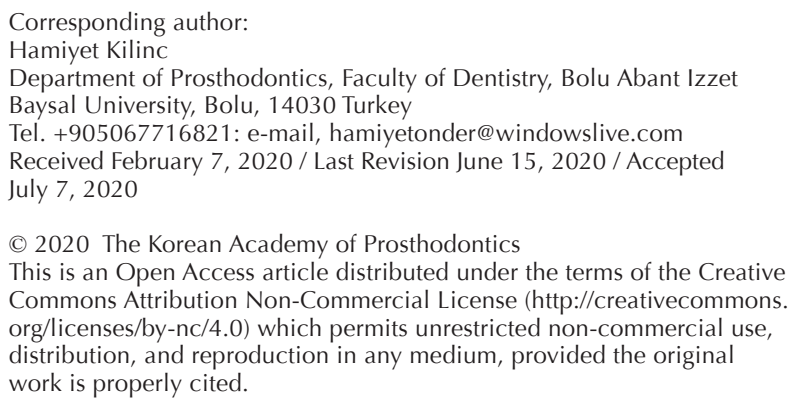

years. ${ }^{3,4}$ Nanoceramics, characterized by the presence of nanoceramic particles bound in the resin matrix, and hybrid ceramics consisting of a fine-structured ceramic network strengthened by an acrylate polymer network are examples of this class of material. ${ }^{2,5}$ Other materials that are compatible with digital dental systems are feldspathic ceramics and glass ceramics. They were produced earlier than the resin ceramics and have been clinically proven many times since their introduction. ${ }^{6,7}$

Compared to the fragile and rigid properties of dental ceramics, the softer characteristics of resin ceramics are advantageous for the milling process. These materials have similar elastic modulus to the human dentine and higher fracture resistance than ceramics, especially for restorations with limited thickness. They can also be produced in a single appointment without requiring a firing process. However, their physically soft and porous structure causes abrasive wear under occlusal forces in the oral environment. ${ }^{8,9}$

According to the manufacturers, resin ceramics offer the 
clinician a high degree of versatility in characterization, adjustment, and repair service intra or extra-orally, either before or after luting the restoration. It was claimed that light-polymerized composites and stains can be bonded directly to these materials with a simple procedure, and this sets resin ceramics apart from feldspathic and glass ceramics. ${ }^{10-12}$ This raises some questions, such as whether resin composite materials can be adhered to the restoration surface after machine milling and whether these CAD/CAM materials, if subjected to occlusal wear over time, can be repaired properly with efficient methods. The main problem in repairing CAD/CAM materials has been obtaining an optimum bond strength between these two materials without long-term adhesive problems. ${ }^{13}$ It was particularly important that durable connection be maintained against chewing forces and intraoral conditions over a longer period. ${ }^{12,13}$ According to the manufacturer's recommendations, this procedure includes applying appropriate surface treatment and the use of adhesive systems, followed by applying a light-polymerized resin composite. ${ }^{14}$

Previous studies examining the repair methods of prosthetic materials have indicated that both mechanical and chemical surface treatments are required. ${ }^{15}$ One of the most used methods for mechanical surface treatment is the use of air abrasion. ${ }^{13}$ The surface area can be increased with this method by forming micro-porosities into which a bonding agent can penetrate and interlock these areas. ${ }^{13,15}$ Hydrofluoric acid etching of the ceramic surface has been evaluated as a chemical surface treatment in several previous studies that reported that it may be clinically beneficial to create pits on the bonding surface. ${ }^{16-18}$ It has also been determined that using erbium, chromium: yttrium-scandium-gallium-garnet (Er,Cr: YSGG) laser irradiation enhances the bond strength of restorative materials by creating micro-retentive areas. ${ }^{19,20}$

Several studies that investigated the repair methods of resin ceramics are available in the literature. ${ }^{12,13,15}$ However, most recent investigations were limited to evaluating laser application and its impact on shear bond strength (SBS) between resin ceramic CAD/CAM materials and light- polymerized resin composite. ${ }^{13,15}$ Beyond those, there are few studies comparatively investigating the repair efficacy of different aged and non-aged CAD/CAM materials. ${ }^{15}$ Since resin ceramics are relatively new materials, further data either before or after clinical use are notably lacking. Thus, the objective of the present research was to investigate the efficacies of diverse surface treatments (control, air abrasion, hydrofluoric acid etching, and Er,Cr:YSGG laser irradiation) on the SBS of aged and non-aged CAD/CAM materials on resin composite material. The null hypotheses were determined as follows: no differences will be observed in the SBS values of CAD/CAM materials and resin composite related to (i) the type of materials, (ii) the type of surface treatments, and (iii) the aging condition (non-aged and aged).

\section{MATERIALS AND METHODS}

The materials analyzed in the present study are given in Table 1. The specimen size was calculated in accordance with a previous research, ${ }^{6,15}$ and it was calculated that 10 specimens for each group supplied a power of 0.9. One additional specimen was prepared to be used for SEM examinations for each test group. VM and EC blocks were evaluated as the control groups, since their success has been proven many times in clinical and laboratory studies, ${ }^{2,21}$ and it was claimed that the reparability of resin ceramics was higher than these materials. ${ }^{21,22} \mathrm{CAD} / \mathrm{CAM}$ materials were prepared using a sectioning saw (IsoMet 1000 Precision Cutter, Buehler, Lake Bluff, IL, USA) and a disc-shaped blade under running water. Eighty-eight rectangular specimens $(14 \times 12 \mathrm{~mm})$ were obtained for each material, with a thickness of $1.5 \pm 0.01 \mathrm{~mm}$, for a total of 352 specimens $(\mathrm{N}=352)$. Since the crystallization procedure of EC causes no major shrinkage, all specimens were prepared with the same dimension. A standardized surface morphology was obtained for specimens by using 300-, 800-, and 1200-grit silicon carbide papers (Mager Scientific, Dexter, MI, USA) in wet condition for 120 seconds. Subsequently, the speci-

Table 1. Materials used in the current study

\begin{tabular}{|c|c|c|c|}
\hline Material & Manufacturer & Composition wt\% & Lot no. \\
\hline Nanoceramic & $\begin{array}{l}\text { Cerasmart (CE), GC Dental Products, } \\
\text { Leuven, Belgium }\end{array}$ & $\begin{array}{l}\text { Bis-MEPP, UDMA, DMA } 71 \% \text { silica }(20 \mathrm{~nm}) \text {, } \\
\text { barium glass ( } 300 \mathrm{~nm})\end{array}$ & $161104 \mathrm{~A}$ \\
\hline $\begin{array}{l}\text { Polymer infiltrated } \\
\text { ceramic network }\end{array}$ & $\begin{array}{l}\text { Vita Enamic (VE), VITA Zahnfabrik, } \\
\text { Bad Säckingen, Germany }\end{array}$ & UDMA, TEGDMA with $86 \%$ feldspathic ceramic & 38950 \\
\hline Feldspathic ceramic & $\begin{array}{l}\text { Vita Mark II (VM), VITA Zahnfabrik, } \\
\text { Bad Säckingen, Germany }\end{array}$ & $\begin{array}{l}54-64 \% \mathrm{SiO}_{2}, 20-23 \% \mathrm{Al}_{2} \mathrm{O}_{3}, 6-9 \% \mathrm{Na}_{2} \mathrm{O} \\
6-8 \% \mathrm{~K}_{2} \mathrm{O}\end{array}$ & 14640 \\
\hline $\begin{array}{l}\text { Lithium disilicate glass } \\
\text { ceramic }\end{array}$ & $\begin{array}{l}\text { IPS e.max CAD (EC), Ivoclar Vivadent, } \\
\text { Schaan, Liechtenstein }\end{array}$ & $\begin{array}{l}57-80 \% \mathrm{SiO}_{2}, 11-19 \% \mathrm{Li}_{2} \mathrm{O}, 0-13 \% \mathrm{~K}_{2} \mathrm{O} \\
0-11 \% \mathrm{P}_{2} \mathrm{O}_{5}, \mathrm{O}-8 \% \mathrm{ZrO}_{2}, \mathrm{O}-8 \% \mathrm{ZnO}, 0-5 \% \mathrm{Al}_{2} \mathrm{O}_{3} \text {, } \\
0-5 \% \mathrm{MgO}, 0-8 \% \text { Colouring oxides }\end{array}$ & U39605 \\
\hline
\end{tabular}

CE: Cerasmart; VE: Vita Enamic; VM: Vita Mark II; EC: IPS e.max CAD; Bis-MEPP: 2.2-bis (4-methacryloxypolyethoxyphenyl) propane; UDMA: urethane dimethacrylate;

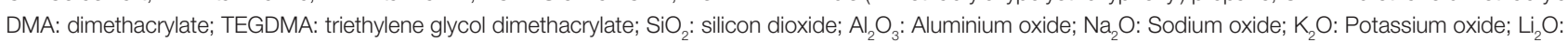
lithium oxide; $\mathrm{P}_{2} \mathrm{O}_{5}$ : Phosphorus pentoxide; $\mathrm{ZrO}_{2}$ : Zirconium dioxide; $\mathrm{ZnO}$ : Zinc oxide; MgO: Magnesium oxide. 
mens were ultrasonically cleaned (ProSonic 600-MTH, Sultan Healthcare Inc., Englewood, NJ, USA) in distilled water for 10 seconds to eliminate any possible contamination. A crystallization firing was then conducted for EC specimens in a ceramic furnace (Programat P 300, Ivoclar Vivadent, Schaan, Liechtenstein) according to the manufacturer's instructions $\left(403^{\circ} \mathrm{C}\right.$ stand-by temperature, 6 minutes closing time, $90^{\circ} \mathrm{C} /$ minute heating rate up to $840^{\circ} \mathrm{C}$ ). The EC specimens were removed from the furnace after completion of the firing cycle and allowed to cool to room temperature.

The specimens were embedded into self-polymerizing acrylic resin (Meliodent, Heraeus Kulzer, Hanau, Germany) with one surface completely exposed using a custom-made cylindrical shaped teflon mold $(20 \times 20 \mathrm{~mm})$. Before the experiment, the exposed analysis surfaces of the specimens were carefully examined and surface irregularities were eliminated if necessary. The obtained specimens per material were divided into two groups as aged and non-aged. Thermal cycles were conducted between $5-55^{\circ} \mathrm{C}$ with 30 seconds of dwell time and 5 seconds of transfer time. ${ }^{23}$ Forty-four aged and 44 non-aged rectangular specimens of each material were then divided into 4 subgroups based on surface treatments by simple randomization to eliminate any possible bias that may arise in the experiment. A computer program was used to generate random numbers. The surface treatment groups are described below $(n=11)$.

Group C: No additional surface treatment was carried out (control).

Group A: Air abrasion with $50 \mu \mathrm{m} \mathrm{Al}_{2} \mathrm{O}_{3}$ particles (Korox, Bego, Bremen, Germany) with CoJet intraoral sandblasting device at a distance of $10 \mathrm{~mm}$ under $3 \mathrm{bar}$ pressure for 20 seconds. ${ }^{15}$

Group E: Conditioning with 5\% hydrofluoric acid (HF) gel (Vita Adiva Cera-Etch, Vita Zahnfabrik, Bad Säckingen, Germany) according to manufacturer's recommendations and previous investigations. ${ }^{6,21} \mathrm{CS}, \mathrm{VE}$, and VM specimens were applied with HF for 60 seconds; while the etching time was 20 seconds for EC, as the conditioning time varied for per material. All specimens were rinsed and gently air-dried after HF application.
Group L: Irradiating using Er,Cr:YSGG laser (Waterlase MD; Biolase Technology Inc., Irvine, CA, USA) with 2780 $\mathrm{nm}$ wavelengths and an 800- $\mu \mathrm{m}$ diameter quartz tip. A hand piece was used in contact hard-tissue mode at $2 \mathrm{~W}$ power, $20 \mathrm{mHz}$ frequency, and $140 \mu \mathrm{s}$ pulse period with $60 \%$ air and $50 \%$ water at a distance of $5 \mathrm{~mm}$ for 40 seconds with a circular motion. ${ }^{21,24}$

All samples were ultrasonically cleaned for the second time following surface treatments as described above. One randomly selected specimen from each group was gold coated and processed for scanning electron microscopy (SEM, JEOL Ltd., Tokyo, Japan) observations at 2500× magnification by 2 experienced evaluators (HK and FAS) for analysis of the surface topography. ${ }^{6}$ Thereafter, the repair procedure was performed. A polyethylene tube $(3 \times$ $0.1 \mathrm{~mm}$ ) was placed on the center of the specimen surfaces for controlling the repair site. ${ }^{6,15}$ An adhesive agent (Single Bond Universal Adhesive, 3M ESPE, Neuss, Germany) was applied to the repair area with a microbrush, gently airdried, and light-polymerized for 20 seconds. A custommade separable teflon mold with an inside diameter of 3 $\mathrm{mm}$ was placed on the bonding area. Resin composite material (Filtek Z550, 3M ESPE, St. Paul, MN, USA) was condensed into the mold in 2-mm incremental layers. Each layer was light polymerized for 40 seconds using a calibrated device (Elipar S10, 3M ESPE, St. Paul, MN, USA) from all directions. Specimen preparation is illustrated schematically in Fig. 1. All specimens were stored in distilled water at $37^{\circ} \mathrm{C}$ for 24 hours prior to the SBS test for the complete polymerization of resin composite material. ${ }^{6,24}$

SBS values of the repaired specimens were evaluated using a universal testing machine (Schimadzu AGS-X, $10 \mathrm{~N}$ - 10 kN, Kyoto, Japan). A shear load was applied in a direction parallel to the bonded interface with a crosshead speed of $0.5 \mathrm{~mm} /$ minute until failure was observed. ${ }^{25} \mathrm{SBS}$ values were recorded in newtons $(\mathrm{N})$, then calculated in mega Pascals ( $\mathrm{MPa}$ ) by dividing the failure load by the bonding surface area (in $\left.\mathrm{mm}^{2}\right){ }^{6}$ Fractographic analysis was performed after the SBS test using a stereomicroscope (Olympus BX51M, Tokyo, Japan) at $10 \times$ magnification. ${ }^{15}$ Failure mode was determined as (i) cohesive: within the ceramic or repair-

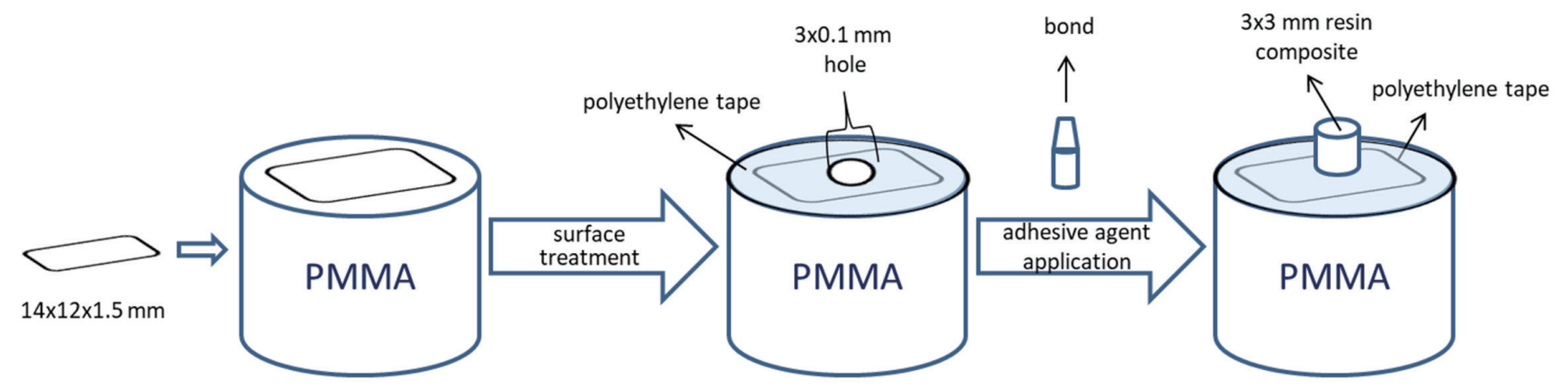

Fig. 1. Schematic view of specimen preparation. 
ing material, (ii) mixed: when cohesive and adhesive fractures were observed at the same time, and (iii) adhesive: between the ceramic and the repair material.

IBM SPSS version 17 (IBM SPSS Statistics, IBM Corporation, Armonk, NY, USA) was used for the data assessment. Statistical analyses were performed using SPSS software (SPSS, Version 17.0, SPSS, Chicago, IL, USA). As the data distribution was normal according to the Kolmogorov-Smirnov test, two-way analysis of variance (ANOVA) was conducted. Post-hoc comparisons were performed using Tukey's Honestly Significant Difference (HSD) test. Dependent variables before and after aging were analyzed using paired-sample t-test. Relative frequencies of failure types were provided. $P \leq .05$ was accepted as significant.

\section{RESULTS}

The mean scores and standard deviations (SDs) of the SBS parameters $(\mathrm{MPa})$ obtained from non-aged and aged specimens are presented in Table 2 and Table 3, respectively. Nonaged VM in combination with HF application resulted in the highest score $(17.91 \pm 0.66)$ (Table 2$)$, while Group $C$ of aged CE showed the lowest $(9.46 \pm 0.81)$ (Table 3). For nonaged and aged conditions, significantly lower mean SBS values were found in Group C compared with other surface treatment groups $(P \leq .05)$, except non-aged CE. Intergroup comparison of the non-aged and aged specimens revealed that feldspathic (VM) and lithium disilicate ceramic (EC) had higher mean SBS values than resin ceramics (CE and VE) $(P$ $\leq .05)$. According to the results of two-way ANOVA (Table 4), the material type, surface treatment type, and their interac-

Table 2. Means \pm SDs of SBS values obtained from non-aged specimens

\begin{tabular}{ccccc}
\hline Material & C & \multicolumn{2}{c}{ Surface treatment } & $E$ \\
\hline CE & $13.29 \pm 0.93^{\mathrm{a} 1}$ & $15.67 \pm 1.34^{\mathrm{ab} 2}$ & $13.75 \pm 1.79^{\mathrm{a} 1}$ & $15.33 \pm 1.73^{\mathrm{a} 2}$ \\
VE & $13.13 \pm 0.81^{\mathrm{ab} 1}$ & $14.56 \pm 1.73^{\mathrm{a} 2}$ & $15.07 \pm 2.42^{\mathrm{a} 2}$ & $15.36 \pm 1.77^{\mathrm{a} 2}$ \\
VM & $13.18 \pm 1.19^{\mathrm{ab} 1}$ & $16.50 \pm 0.75^{\mathrm{b} 2}$ & $17.91 \pm 0.66^{\mathrm{b} 3}$ & $16.75 \pm 2.07^{\mathrm{a} 23}$ \\
EC & $12.16 \pm 0.63^{\mathrm{b} 1}$ & $16.71 \pm 1.54^{\mathrm{b} 2}$ & $17.55 \pm 0.76^{\mathrm{b} 2}$ & $16.18 \pm 2.38^{\mathrm{a} 2}$ \\
\hline
\end{tabular}

SDs: Standard deviations; SBS: Shear bond strength; C: Control; A: Air abrasion; E: Etching; L: Laser irradiation; CE: Cerasmart; VE: Vita Enamic; VM: Vita Mark II; EC: E.max CAD. Different superscript letters ( $a$ and b) in the same column indicate a significant inter group difference in scores, and different superscript numbers (1, 2, and 3) in the same row indicate a significant intra group difference in score $(P \leq .05)$. Data are expressed in MPa.

Table 3. Means \pm SDs of SBS values obtained from aged specimens

\begin{tabular}{|c|c|c|c|c|}
\hline \multirow{2}{*}{ Material } & \multicolumn{4}{|c|}{ Surface treatment } \\
\hline & $\mathrm{C}$ & $A$ & $E$ & $L$ \\
\hline CE & $9.46 \pm 0.81^{\times 1}$ & $13.21 \pm 1.03^{x y 2}$ & $12.51 \pm 0.81^{\times 2}$ & $12.90 \pm 0.58^{\times 2}$ \\
\hline VE & $9.98 \pm 0.73^{x y 1}$ & $12.85 \pm 1.02^{\times 2}$ & $13.49 \pm 1.15^{\times 2}$ & $13.45 \pm 1.20^{\times 2}$ \\
\hline VM & $10.79 \pm 0.84^{y 1}$ & $13.28 \pm 0.86^{x y 2}$ & $15.45 \pm 0.57^{y 3}$ & $14.03 \pm 0.94^{\times 2}$ \\
\hline EC & $10.83 \pm 0.86^{y 1}$ & $14.32 \pm 0.98^{y 23}$ & $15.61 \pm 1.31^{\mathrm{y} 2}$ & $13.94 \pm 1.64^{\times 3}$ \\
\hline
\end{tabular}

SDs: Standard deviations; SBS: Shear bond strength; C: Control; A: Air abrasion; E: Etching; L: Laser irradiation; CE: Cerasmart; VE: Vita Enamic; VM: Vita Mark Il; EC: E.max CAD. Different superscript letters $(x$ and $y)$ in the same column indicate a significant intra group difference in scores, and different superscript numbers $(1,2$, and $3)$ in the same row indicate a significant inter group difference in scores $(P \leq .05)$. Data are expressed in MPa.

Table 4. Results of two-way ANOVA

\begin{tabular}{|c|c|c|c|c|c|c|c|c|}
\hline \multirow{2}{*}{ Source } & \multicolumn{4}{|c|}{ Non-aged condition } & \multicolumn{4}{|c|}{ Aged condition } \\
\hline & $d f$ & MS & $\mathrm{F}$ & $P$ & $d f$ & MS & $\mathrm{F}$ & $P$ \\
\hline Material type & 3 & 25.47 & 13.84 & $<.001$ & 3 & 23.20 & 23.32 & $<.001$ \\
\hline Surface treatment type & 3 & 90.49 & 49.19 & $<.001$ & 3 & 128.73 & 129.39 & $<.001$ \\
\hline Material $\times$ surface treatment type & 9 & 10.45 & 5.68 & $<.001$ & 9 & 3.64 & 3.66 & $<.001$ \\
\hline
\end{tabular}


tions were significant with regard to SBS $(P<.001)$. The aging condition before repair (being aged or non-aged) also had a significant effect on SBS values $(P<.001)$ based on the results of paired-sample t-test (Table 5). Significant differences were obtained among SBS values of non-aged and aged specimens for all groups (except in the etched CE and VE).

The failure types are presented in Table 6. Mostly adhesive failures were observed in the control groups of all materials in both aging conditions. Etched VM and EC materials showed predominantly mixed failure type. Mostly mixed failure $(60 \%)$ was observed in the laser-irradiated group for the non-aged VE. However, cohesive failures in CAD/CAM materials were rarely observed (only for $\mathrm{HF}$-etched VM and
$\mathrm{EC})$.

Representative images obtained from SEM analysis of CAD/CAM materials after surface treatments are shown in Fig. 2, Fig. 3, Fig. 4, and Fig. 5. Different surface treatments resulted in differences in surface topography of the aged and non-aged specimens. The air-abraded surfaces had slightly more surface irregularities in CE for both aging conditions. HF etching and laser irradiation generated moderate and deep irregularities on the VE surface. HF etching created generalized irregular surfaces with micro-retentive areas for VM and EC. The effects of surface treatments were slightly more prominent on non-aged specimens than on aged specimens.

Table 5. Results of paired-sample t test

\begin{tabular}{|c|c|c|c|c|}
\hline Surface treatments & Material & $\mathrm{SBS} \pm \mathrm{SDs}$ (non-aged) & $\mathrm{SBS} \pm \mathrm{SD}$ (aged) & $P$ \\
\hline \multirow{4}{*}{ C } & CE & $13.29 \pm 0.93^{a}$ & $9.46 \pm 0.81^{b}$ & $<.001$ \\
\hline & VE & $13.13 \pm 0.81^{\mathrm{a}}$ & $9.98 \pm 0.73^{b}$ & $<.001$ \\
\hline & VM & $13.18 \pm 1.19^{a}$ & $10.79 \pm 0.84^{b}$ & .001 \\
\hline & EC & $12.16 \pm 0.63^{a}$ & $10.83 \pm 0.86^{b}$ & .005 \\
\hline \multirow{4}{*}{ A } & CE & $15.67 \pm 1.34^{a}$ & $13.21 \pm 1.03^{b}$ & .002 \\
\hline & VE & $14.56 \pm 1.73^{\mathrm{a}}$ & $12.85 \pm 1.02^{b}$ & .032 \\
\hline & VM & $16.50 \pm 0.75^{a}$ & $13.28 \pm 0.86^{b}$ & $<.001$ \\
\hline & EC & $16.71 \pm 1.54^{a}$ & $14.32 \pm 0.98^{b}$ & .003 \\
\hline \multirow{4}{*}{$E$} & CE & $13.75 \pm 1.79^{a}$ & $12.51 \pm 0.81^{a}$ & .091 \\
\hline & VE & $15.07 \pm 2.42^{a}$ & $13.49 \pm 1.15^{a}$ & .077 \\
\hline & VM & $17.91 \pm 0.66^{a}$ & $15.45 \pm 0.57^{b}$ & $<.001$ \\
\hline & EC & $17.55 \pm 0.76^{a}$ & $15.61 \pm 1.31^{b}$ & .002 \\
\hline \multirow{4}{*}{$L$} & CE & $15.33 \pm 1.73^{a}$ & $12.90 \pm 0.58^{b}$ & .001 \\
\hline & VE & $15.36 \pm 1.77^{\mathrm{a}}$ & $13.45 \pm 1.20^{b}$ & .006 \\
\hline & VM & $16.75 \pm 2.07^{a}$ & $14.03 \pm 0.94^{b}$ & .003 \\
\hline & EC & $16.18 \pm 2.38^{a}$ & $13.94 \pm 1.64^{b}$ & .020 \\
\hline
\end{tabular}

SBS: Shear Bond strength; SDs: Standard deviations C: Control; A: Air abrasion; E: Etching; L: Laser irradiation; CE: Cerasmart; VE: Vita Enamic; VM: Vita Mark II; EC: E.max CAD. Different superscript letters $(a$ and $b)$ in the same row indicate a significant intergroup difference in scores $(P \leq .05)$. Data are expressed in MPa.

Table 6. Failure percentages of the groups

\begin{tabular}{|c|c|c|c|c|c|}
\hline \multirow{2}{*}{ Surface treatment } & \multirow{2}{*}{ Material type } & \multirow{2}{*}{ Aging type } & \multicolumn{3}{|c|}{ Failure types } \\
\hline & & & Adhesive & Cohesive & Mixed \\
\hline \multirow{8}{*}{ Control } & \multirow{2}{*}{ CE } & Non-aged & 90 & - & 10 \\
\hline & & Aged & 100 & - & 0 \\
\hline & \multirow{2}{*}{ VE } & Non-aged & 90 & - & 10 \\
\hline & & Aged & 90 & - & 10 \\
\hline & \multirow{2}{*}{ VM } & Non-aged & 90 & - & 10 \\
\hline & & Aged & 100 & - & 0 \\
\hline & \multirow{2}{*}{ EC } & Non-aged & 80 & - & 20 \\
\hline & & Aged & 100 & - & 0 \\
\hline
\end{tabular}


Table 6. (Continued) Failure percentages of the groups

\begin{tabular}{|c|c|c|c|c|c|}
\hline \multirow{2}{*}{ Surface treatment } & \multirow{2}{*}{ Material type } & \multirow{2}{*}{ Aging type } & \multicolumn{3}{|c|}{ Failure types } \\
\hline & & & Adhesive & Cohesive & Mixed \\
\hline \multirow{8}{*}{ Air abrasion } & \multirow{2}{*}{ CE } & Non-aged & 50 & - & 50 \\
\hline & & Aged & 80 & - & 20 \\
\hline & \multirow{2}{*}{ VE } & Non-aged & 60 & - & 40 \\
\hline & & Aged & 70 & - & 30 \\
\hline & \multirow{2}{*}{ VM } & Non-aged & 70 & - & 30 \\
\hline & & Aged & 80 & - & 20 \\
\hline & \multirow[b]{2}{*}{ EC } & Non-aged & 70 & - & 30 \\
\hline & & Aged & 80 & - & 20 \\
\hline \multirow{8}{*}{ Hydrofluoric acid etching } & \multirow{2}{*}{ CE } & Non-aged & 80 & - & 20 \\
\hline & & Aged & 90 & - & 10 \\
\hline & \multirow{2}{*}{ VE } & Non-aged & 80 & - & 20 \\
\hline & & Aged & 60 & - & 40 \\
\hline & \multirow{2}{*}{ VM } & Non-aged & 20 & 30 & 50 \\
\hline & & Aged & 40 & 10 & 50 \\
\hline & \multirow{2}{*}{$\mathrm{EC}$} & Non-aged & 10 & 10 & 80 \\
\hline & & Aged & 40 & 10 & 50 \\
\hline \multirow{8}{*}{ Laser irradiation } & \multirow{2}{*}{ CE } & Non-aged & 90 & - & 10 \\
\hline & & Aged & 90 & - & 10 \\
\hline & \multirow{2}{*}{ VE } & Non-aged & 40 & - & 60 \\
\hline & & Aged & 80 & - & 20 \\
\hline & \multirow{2}{*}{ VM } & Non-aged & 70 & - & 30 \\
\hline & & Aged & 80 & - & 20 \\
\hline & \multirow{2}{*}{ EC } & Non-aged & 70 & - & 30 \\
\hline & & Aged & 70 & - & 30 \\
\hline
\end{tabular}

CE: Cerasmart; VE: Vita Enamic; VM: Vita Mark II; EC: E.max CAD
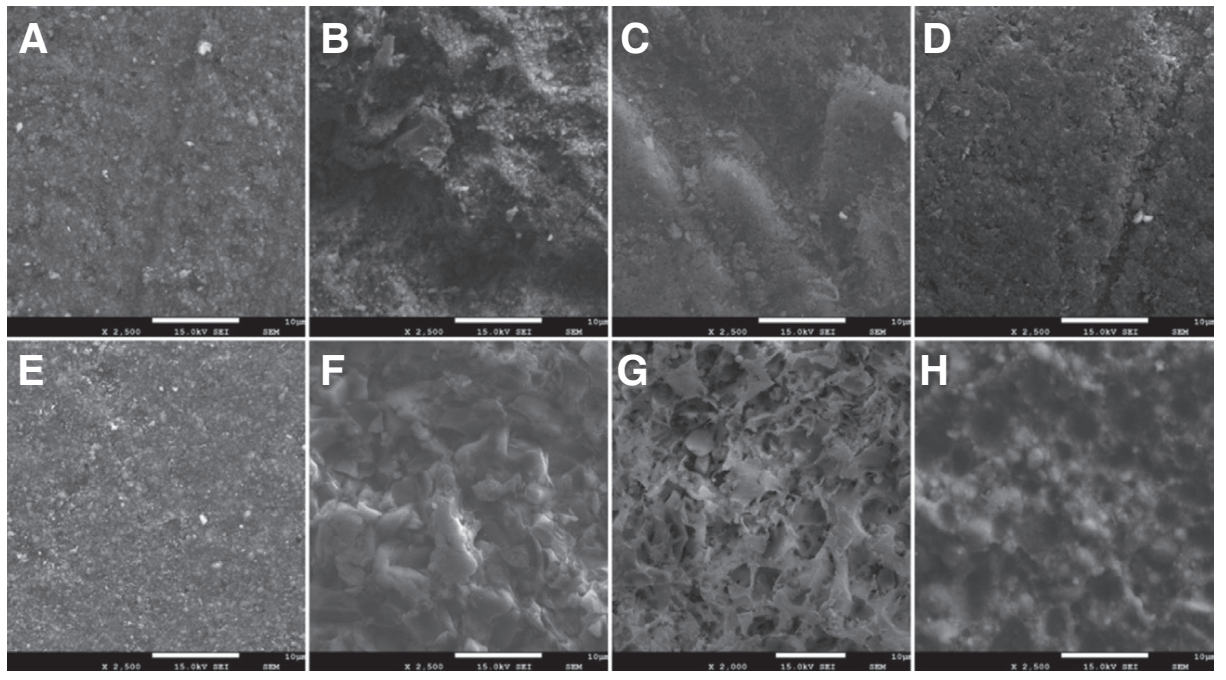

Fig. 2. SEM images at 2500× magnification of non-aged CE and VE. (A) Control CE, (B) Air abraded CE, (C) Acid etched $C E$, (D) Laser irradiated CE, (E) Control VE, (F) Air abraded VE, (G) Etched VE, (H) Laser irradiated VE. 


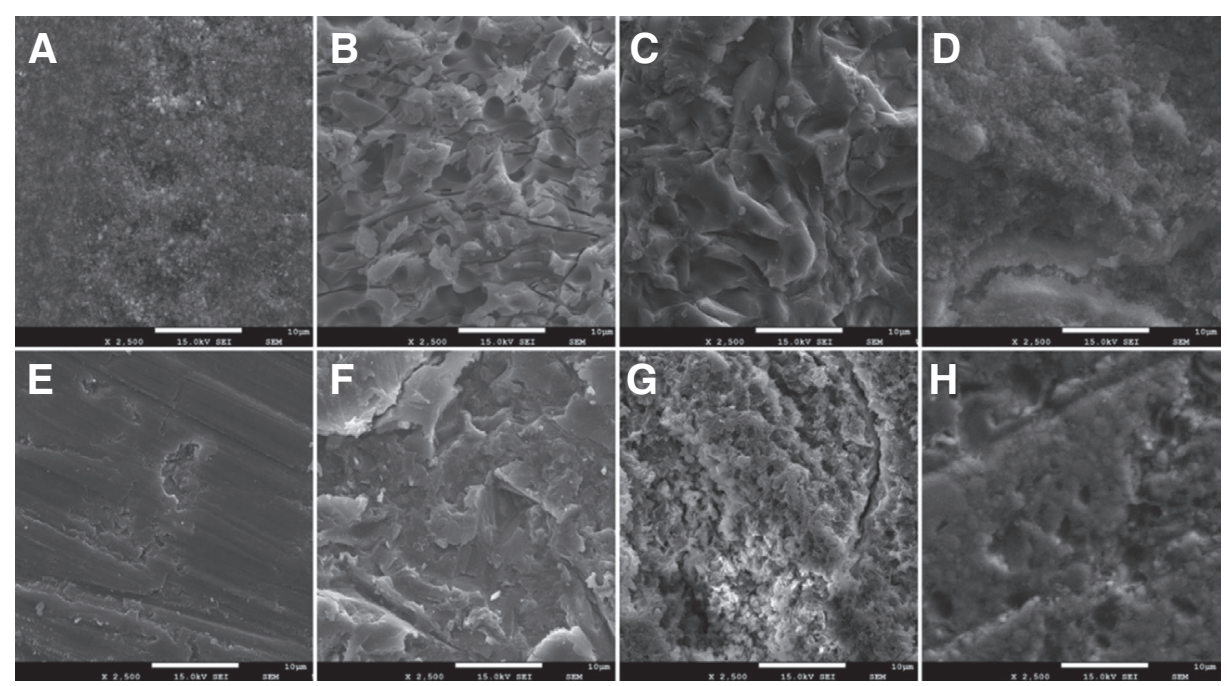

Fig. 3. SEM images at 2500× magnification of non-aged VM and EC. (A) Control VM, (B) Air abraded VM, (C) Acid etched VM, (D) Laser irradiated VM, (E) Control EC, (F) Air abraded EC, (G) Etched EC, (H) Laser irradiated.

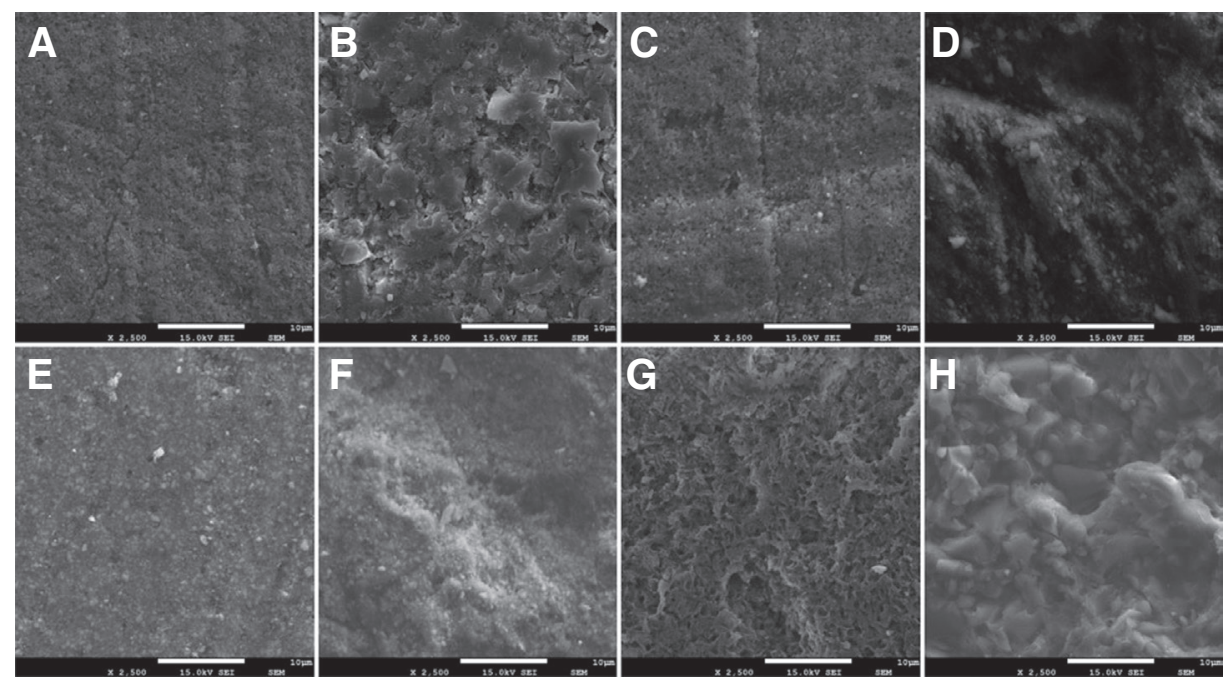

Fig. 4. SEM images at 2500x magnification of aged CE and VE. (A) Control CE, (B) Air abraded CE, (C) Acid etched CE, (D) Laser irradiated CE, (E) Control VE, (F) Air abraded VE, (G) Etched VE, (H) Laser irradiated VE.

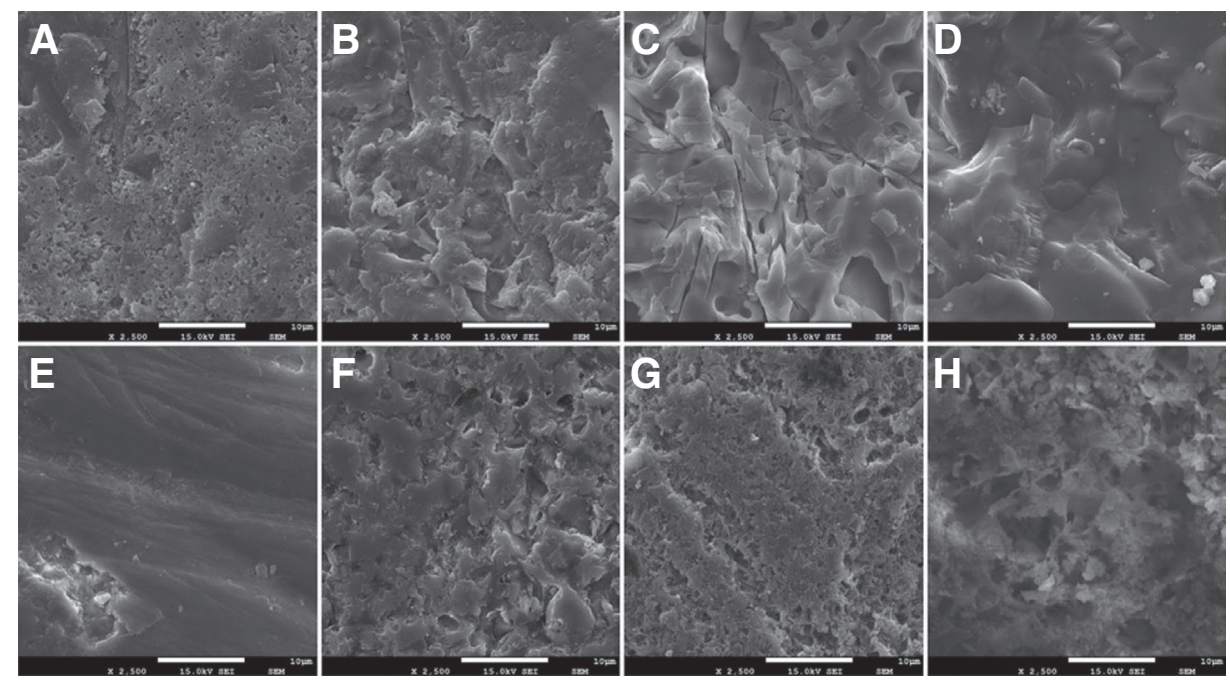

Fig. 5. SEM images at 2500× magnification of aged VM and EC. (A) Control VM, (B) Air abraded VM, (C) Acid etched VM, (D) Laser irradiated VM, (E) Control EC, (F) Air abraded EC, (G) Etched EC, (H) Laser irradiated EC. 


\section{DISCUSSION}

The effectiveness of the various surface treatment methods was significantly different for the analyzed CAD/CAM materials. Ceramics/glass ceramics showed significantly higher mean SBS values than the resin ceramics after applying different surface treatments $(P<.001)$. Therefore, the first null hypothesis - no differences will be observed in the SBS values of CAD/CAM materials and resin composite related to the type of materials - was rejected. This variance in the effectiveness of surface treatments determined for the different materials may be attributed to different chemical formulations of tested materials. The results of the present research are in agreement with previous studies, which reported that the behavior of materials subjected to surface treatments might vary depending on their chemical content. ${ }^{10,13}$ The surface treatment should be selected according to the type of material. ${ }^{10,17}$

The second null hypothesis - no differences will be observed in the SBS values of CAD/CAM materials and resin composite related to the type of surface treatments was also rejected. The SBS values of the current study were significantly affected by diverse surface treatments in both non-aged and aged conditions $(P<.001)$. Among all the tested materials, control groups (except non-aged CE) presented lower SBS values, in accordance with those of previous studies. ${ }^{13,26}$

Significant differences were observed between SBS values of non-aged and aged specimens except in the etched CE and VE (Table 5). The results of the present study revealed that the aging condition (being aged or non-aged) was an important factor in obtaining durable bond strength for the tested materials. Thus, the third null hypothesis - no differences will be observed in the SBS values of CAD/ CAM materials and resin composite related to the aging condition (non-aged and aged) - was rejected. This study was consistent with a previous research, which reported that the thermal aging process had a significant effect on SBS values between resin nanoceramics and resin composite. ${ }^{15}$ The SBS scores that decreased after the aging process indicated that it might be difficult to obtain sufficient bond strength with a repair process performed after the intraoral use of a restoration. This decrease could correspond with the water sorption of the ceramic due to artificial aging. Light-polymerized resin composite materials can adhere more successfully to non-aged surfaces than to aged ones.

The bond strength between two materials can be evaluated using multiple methods. The SBS test was used in this study as it was a popular and practical bond test. ${ }^{6}$ Specimens were tested after surface standardization using abrasive papers in this study, in accordance with several previous studies evaluating repair bond strength between CAD/CAM materials and resin composites. ${ }^{6,10,11,13,15,27}$ Polishing or glazing was omitted to ensure that the results of the current study were comparable to previous studies. Besides, the exposed surface to be repaired after chipping is not a polished surface. Intraoral repair process is applied to the unpolished restoration surface. It should be noted that applying polishing or glazing to material may alter the obtained SBS values.

Mechanical and chemical surface treatments principally clean the adherent surface and increase the surface energy and wettability, resulting in an improvement in restoration and repair material bonding. ${ }^{28-30}$ Various types of surface treatments were used in the present study as different methods have been proposed to achieve durable bond strength for tested materials. In the present study, HF application showed better results considering higher SBS values (Table 2, Table 3) $(P>.05)$ and observed cohesive failure types (Table 6 ) in both aging conditions for VM and EC. HF etching is considered to be a gold standard for ceramics as the glassy content is dissolved and the crystalline phase becomes visible. ${ }^{21} \mathrm{HF}$ etching is suggested for VE, VM, and EC by their respective manufacturers, although both HF etching and air abrasion can be applicable for CE. However, it has been reported in a previous study that all the recommended surface treatments resulted in a reduction in flexural strength of EC, VE, and CE, since these treatments caused mechanical stress and microfractures at the restoration surfaces. ${ }^{21}$ Further investigations that include the effects of different repair materials and adhesive agents on the mechanical properties of final restorations will be beneficial.

HF etching was more effective in achieving durable bond strength for VM and EC than for resin ceramics (CE and VE) (Table 2, Table 3; $P \leq .05$ ). Non-aged CE in combination with HF application showed lower SBS values compared with air abrasion and laser irradiation (Table 2) $(P$ $\leq .05)$. VE resulted in similar SBS values with air abrasion, HF etching, and laser applications in both aging conditions. These results might be due to the different ratio and distribution of the glassy content of tested materials being affected by HF etching. Group C of all tested materials presented the lowest SBS values (Table 2, Table 3$)(P \leq .05)$, and this difference was not significant for only HF etching group of non-aged CE. The results were compatible with the findings of previous studies suggesting that surface treatments should be performed prior the repairing procedure. $^{31-33}$

Er,Cr:YSGG laser is another surface treatment technique that has been indicated to enhance the SBS between $\mathrm{CAD} / \mathrm{CAM}$ materials and resin composite. This type of laser is irradiated at a $2.78 \mu \mathrm{m}$ wavelength, which matches the absorption peak of water. ${ }^{34}$ Thus, it can be greatly absorbed by either water or hydroxyapatite crystals. Microexplosions occur as a result of the vaporization formed by the absorption of laser energy and result in macroscopic and microscopic irregularities on the material surface. ${ }^{24}$ Several investigations have examined the efficacy of laser application on the SBS between CAD/CAM materials and resin composite/resin cement. ${ }^{35,36}$ Ozarslan et al. ${ }^{35}$ assessed the SBS of ceramic brackets to CAD/CAM blocks (VE and Lava Ultimate) after various surface treatments, and they reported that sandblasting and HF application resulted in 
higher SBS values than Er,Cr:YSGG laser irradiation for both materials. In the present study, air abrasion and laser irradiation significantly improved the SBS values between non-aged CE and resin composite. Laser irradiation also resulted in the highest SBS value for non-aged VE, but there were no significant differences between the Groups L, $\mathrm{E}$, and A. Cho et al. ${ }^{24}$ investigated the effect of Er,Cr:YSGG laser on repair bond strength of resin composites and concluded that significantly lower SBS values were determined after laser irradiation at 4-W power than those of air abrasion with $50 \mu \mathrm{m} \mathrm{Al} \mathrm{O}_{3}$ and tribochemical silica coating. Group L showed significantly better results compared with Group C for all evaluated materials in the current study (Table 2, Table 3) $(P \leq .05)$. The type of material used and the energy settings of the laser can affect the results. In this study, current monolithic CAD/CAM restorations were investigated after laser application at the 2-W energy level.

SEM micrographs and fracture type analyzes are used to evaluate the bond strength generated between the tested materials in many studies. ${ }^{6,15,23,37,38}$ Adhesive failure is associated with decreased SBS, while cohesive failure is corresponded with improved SBS. ${ }^{37}$ Adhesive failure type was mostly observed in this study. Cohesive failure was formed only in HF-etched VM and EC (Table 6). This result was in accordance with the higher bond strengths of HF-treated ceramic CAD/CAM materials. ${ }^{6,38}$ HF-etched VM and EC specimens showed a surface on which grooves, pits, and fissures generated improved micromechanical retention of the light-polymerized resin composite material. This improvement is believed to be due to the fact that HF-etched ceramic/glass ceramic surfaces showed a roughened surface that could increase the wettability for an adhesive agent. Group C in all 4 materials showed the smoothest surface compared to the other evaluated surface treatments (Fig. 2, Fig. 3, Fig. 4, Fig. 5). This may be attributed to the lower bond strengths of the control groups.

Preparing specimens with flat surfaces unlike anatomic surfaces of natural teeth and using only one type of adhesive system are considered limitations of the current study. Clinical studies will be needed to further investigate the influence of different laser applications with varying energy levels and adhesive systems on SBS generated between resin composite and CAD/CAM materials.

\section{CONCLUSION}

Surface treatment before the repair procedure should be conducted in all cases to enhance the CAD/CAM materials and resin composite bond strength. HF etching was more effective in achieving durable bond strength for ceramics/ glass ceramics (VM and EC) than for resin ceramics (VE and $\mathrm{CE}$ ). Laser irradiation could be recommended as an alternative surface treatment method to HF etching and air abrasion for all tested materials in both aging conditions. Aging had a significant effect on SBS values generated between tested materials and resin composite.

\section{ORCID}

Hamiyet Kilinc https://orcid.org/0000-0001-8055-3470

Fatma Ayse Sanal https://orcid.org/0000-0002-2864-6589

Sedanur Turgut bttps://orcid.org/0000-0003-2534-9279

\section{REFERENCES}

1. Elsaka SE, Elnaghy AM. Mechanical properties of zirconia reinforced lithium silicate glass-ceramic. Dent Mater 2016;32: 908-14.

2. Kilinc H, Turgut S. Optical behaviors of esthetic CAD-CAM restorations after different surface finishing and polishing procedures and UV aging: An in vitro study. J Prosthet Dent 2018;120:107-13.

3. Fasbinder DJ. Materials for chairside CAD/CAM restorations. Compend Contin Educ Dent 2010;31:702-9.

4. Spitznagel FA, Horvath SD, Guess PC, Blatz MB. Resin bond to indirect composite and new ceramic/polymer materials: a review of the literature. J Esthet Restor Dent 2014;26:382-93.

5. El Zhawi H, Kaizer MR, Chughtai A, Moraes RR, Zhang Y. Polymer infiltrated ceramic network structures for resistance to fatigue fracture and wear. Dent Mater 2016;32:1352-61.

6. Carrabba M, Vichi A, Louca C, Ferrari M. Comparison of traditional and simplified methods for repairing CAD/CAM feldspathic ceramics. J Adv Prosthodont 2017;9:257-64.

7. Baldissara P, Wandscher VF, Marchionatti AME, Parisi C, Monaco C, Ciocca L. Translucency of IPS e.max and cubic zirconia monolithic crowns. J Prosthet Dent 2018;120:269-75.

8. Lawson NC, Janyavula S, Syklawer S, McLaren EA, Burgess JO. Wear of enamel opposing zirconia and lithium disilicate after adjustment, polishing and glazing. J Dent 2014;42:158691.

9. D’Arcangelo C, Vanini L, Rondoni GD, Pirani M, Vadini M, Gattone M, Angelis FD. Wear properties of a novel resin composite compared to human enamel and other restorative materials. Oper Dent 2014;39:612-8.

10. Elsaka SE. Repair bond strength of resin composite to a novel CAD/CAM hybrid ceramic using different repair systems. Dent Mater J 2015;34:161-7.

11. Üstün Ö, Büyükhatipoğlu IK, Seçilmiş A. Shear Bond Strength of Repair Systems to New CAD/CAM Restorative Materials. J Prosthodont 2018;27:748-54.

12. Güngör MB, Nemli SK, Bal BT, Ünver S, Doğan A. Effect of surface treatments on shear bond strength of resin composite bonded to CAD/CAM resin-ceramic hybrid materials. J Adv Prosthodont 2016;8:259-66.

13. Stawarczyk B, Krawczuk A, Ilie N. Tensile bond strength of resin composite repair in vitro using different surface preparation conditionings to an aged CAD/CAM resin nanoceramic. Clin Oral Investig 2015;19:299-308.

14. Jeong KW, Kim SH. Influence of surface treatments and repair materials on the shear bond strength of CAD/CAM provisional restorations. J Adv Prosthodont 2019;11:95-104.

15. Subaşı MG, Alp G. Repair bond strengths of non-aged and aged resin nanoceramics. J Adv Prosthodont 2017;9:364-70.

16. Puppin-Rontani J, Sundfeld D, Costa AR, Sinhoreti M, 
Correr-Sobrinho L. Effect of hydrofluoric acid concentration and etching time on bond strength to lithium disilicate glass ceramic. Oper Dent 2017;42:606-15.

17. Klosa K, Boesch I, Kern M. Long-term bond of glass ceramic and resin cement: evaluation of titanium tetrafluoride as an alternative etching agent for lithium disilicate ceramics. J Adhes Dent 2013;15:377-83.

18. Chen JH, Matsumura H, Atsuta M. Effect of etchant, etching period, and silane priming on bond strength to porcelain of composite resin. Oper Dent 1998;23:250-7.

19. Vohra F, Labban N, Al-Hussaini A, Al-Jarboua M, Zawawi R, Alrahlah A, Naseem M. Influence of Er;Cr:YSGG laser on shear bond strength and color stability of lithium disilicate ceramics: an in vitro study. Photobiomodul Photomed Laser Surg 2019;37:483-8.

20. Tokar E, Polat S, Ozturk C. Repair bond strength of composite to Er,Cr:YSGG laser irradiated zirconia and porcelain surfaces. Biomed J 2019;42:193-9.

21. Kurtulmus-Yilmaz S, Cengiz E, Ongun S, Karakaya I. The effect of surface treatments on the mechanical and optical behaviors of CAD/CAM restorative materials. J Prosthodont 2019;28:e496-503.

22. Coldea A, Swain M, Thiel N. Mechanical properties of polymer-infiltrated-ceramic-network materials. Dent Mater 2013; 29:419-26.

23. Morresi AL, D’Amario M, Capogreco M, Gatto R, Marzo G, D'Arcangelo C, Monaco A. Thermal cycling for restorative materials: Does a standardized protocol exist in laboratory testing? A literature review. J Mech Behav Biomed Mater 2014;29:295-308.

24. Cho SD, Rajitrangson P, Matis BA, Platt JA. Effect of Er,Cr: YSGG laser, air abrasion, and silane application on repaired shear bond strength of composites. Oper Dent 2013;38:e1-9.

25. Çinar S, Kırmalı Ö. Repair bond strength of composite resin to zirconia restorations after different thermal cycles. J Adv Prosthodont 2019;11:297-304.

26. Wiegand A, Stucki L, Hoffmann R, Attin T, Stawarczyk B. Repairability of CAD/CAM high-density PMMA- and composite-based polymers. Clin Oral Investig 2015;19:2007-13.

27. Silva PNFD, Martinelli-Lobo CM, Bottino MA, Melo RM, Valandro LF. Bond strength between a polymer-infiltrated ceramic network and a composite for repair: effect of several ceramic surface treatments. Braz Oral Res 2018;32:e28.

28. D'Arcangelo C, Vanini L. Effect of three surface treatments on the adhesive properties of indirect composite restorations. J Adhes Dent 2007;9:319-26.

29. Marshall SJ, Bayne SC, Baier R, Tomsia AP, Marshall GW. A review of adhesion science. Dent Mater 2010;26:e11-6.

30. Naves LZ, Soares CJ, Moraes RR, Gonçalves LS, Sinhoreti MA, Correr-Sobrinho L. Surface/interface morphology and bond strength to glass ceramic etched for different periods. Oper Dent 2010;35:420-7.

31. Stawarczyk B, Liebermann A, Eichberger M, Güth JF. Evaluation of mechanical and optical behavior of current esthetic dental restorative CAD/CAM composites. J Mech Behav Biomed Mater 2015;55:1-11.

32. Lawson NC, Bansal R, Burgess JO. Wear, strength, modulus and hardness of CAD/CAM restorative materials. Dent Mater 2016;32:e275-83.

33. Lauvahutanon S, Takahashi H, Oki M, Arksornnukit M, Kanehira M, Finger WJ. In vitro evaluation of the wear resistance of composite resin blocks for CAD/CAM. Dent Mater J 2015;34:495-502.

34. Hibst R, Keller U. Experimental studies of the application of the Er:YAG laser on dental hard substances: I. Measurement of the ablation rate. Lasers Surg Med 1989;9:338-44.

35. Ozarslan MM, Ustun O, Buyukkaplan US, Barutcigil C, Turker N, Barutcigil K. Assessment the bond strength of ceramic brackets to CAD/CAM nanoceramic composite and interpenetrating network composite after different surface treatments. Biomed Res Int 2018;30:1871598.

36. Hou Y, Shen R, Chen L, Chen Y, Jiang Y, Li JM, Gao J. Shear bond strength of different CAD/CAM ceramics: acid vs Er:YAG laser etching. Photomed Laser Surg 2018;36:614-20.

37. Alp G, Subaş1 MG, Johnston WM, Yilmaz B. Effect of different resin cements and surface treatments on the shear bond strength of ceramic-glass polymer materials. J Prosthet Dent 2018;120:454-61.

38. Erdemir U, Sancakli HS, Sancakli E, Eren MM, Ozel S, Yucel T, Yildiz E. Shear bond strength of a new self-adhering flowable composite resin for lithium disilicate-reinforced CAD/ CAM ceramic material. J Adv Prosthodont 2014;6:434-43. 